\title{
Characteristics of Stable Hydrogen and Oxygen Isotopes of Soil Moisture under Different Land Use in Dry Hot Valley of Yuanmou
}

https://doi.org/10.1515/chem-2019-0014

received March 22, 2018; accepted September 16, 2018.

Abstract: Soil moisture, stable hydrogen, and oxygen isotopes were sampled and determined in a demonstration area of soil and moisture conservation at the Laocheng Town of Yuanmou County in Chuxiong Prefecture, Yunnan of three land use types: Leucaena Benth artificial forest, Heteropogon contortus grass field, and farmland. The characteristics of stable hydrogen and oxygen isotopes of soil moisture in these different land use types at different soil depths were analyzed to investigate the regularities in the quantitative formation of soil moisture balance. In terms of forest land, we found that the variable coefficient of hydrogen isotopes in the $0-20 \mathrm{~cm}$ soil layer was the smallest, but decreased with depth under $20 \mathrm{~cm}$. While in grassland, the variable coefficient in $80-100 \mathrm{~cm}$ was the largest, and decreased with depth above $80 \mathrm{~cm}$. As for farmland, the variable coefficient in the top $20 \mathrm{~cm}$ was the largest, followed by $40-60 \mathrm{~cm}$, and the medium 20-40 $\mathrm{cm}$ was the smallest. The soil moisture hydrogen isotope values of three land use type were different at surface layer, but prone to be consistent in each type. Along the soil depth in forest land, the hydrogen isotope increased first and then decreased, while increased in the end, and the maximum appeared in $80-100 \mathrm{~cm}$. In grassland, the hydrogen isotope increased initially as the forest land but then decreased continuously, so the maximum was found at $20-40 \mathrm{~cm}$. And in grassland, the hydrogen isotope of all depths were higher than which of forest land and farmland. In same land use type, the hydrogen isotope of soil moisture changed significantly at the surface, and the

\footnotetext{
*Corresponding author: Yang-Yi Zhao, Southwest Forestry University, Kunming, 650224,Yunnan Province, China; Yuxi Forest Ecosystem Research Station, China's State Forestry Administration, Kunming 650224, China, E-mail: feixue20012360@163.com Jiao-Jiao Han, Xu Duan, Meng Li: Southwest Forestry University, Kunming, 650224,Yunnan Province, China

Xu Duan: Yuxi Forest Ecosystem Research Station, China's State Forestry Administration, Kunming 650224, China
}

variation of hydrogen isotopes was obviously decreased along the depth. Our findings could provide reference data which would contribute to the assessment of regional groundwater resources in the dry-hot valley of Yuanmou in this study.

Keywords: Dry-hot valley; Soil moisture; Stable hydrogen and oxygen isotopes; Land use.

\section{Introduction}

The scarcity of water resources has been one of the major and ever-growing concerns worldwide recently. As a water resource form, soil moisture has attracted the research attention of the international scientific community. It is an important source of water for the life and development of agricultural and natural vegetation, ensuring high global productivity [1,2], energy balance, and transport of substances [3]. Studying soil moisture stable isotopes characteristics id of significance for soil moisture replenishment, water redistribution mechanism [4], nutrient and pollutant [5] transport in the soil, and the assessment of regional water resources [6,7]. Stable isotopes have been widely used to evaluate regional water recharge and evaporation. In particular, they are employed as a geochemical tracer for trace ability analysis. In the last 20 years, the new but already relatively mature stable isotope technology has been increasingly utilized in various hydrogeology fields. For example, the isotope method has been used in examinations of soil moisture utilization and migration, and effective results have been achieved. Therefore, the necessity and feasibility of conducting studies on the stable isotope of soil moisture are clearly demonstrated.

The change of stable isotopes in soil moisture can be affected by precipitation infiltration, surface evaporation, horizontal migration, and vertical movement of soil moisture. Therefore, the changes in the stable isotopes of soil moisture and the isotopic composition, used 
as a natural tracer, can reveal valuable information of the soil moisture flux, including data on evaporation, transpiration, infiltration, which is generally difficult to obtain using other techniques [8-10]. These hydraulic characteristics are then utilized to establish the model of soil moisture movement through the models of Kostiakov, Philip, and Green-Ampt. Foreign research on soil moisture isotopes started early, and in 1953, Dansgaard [11] conducted studies on the oxygen isotopes in atmospheric precipitation. By the 1960s, isotopic tracer methods were employed in investigations of water flow, providing useful information for better understanding soil moisture movement and soil evaporation. Schwen [12] and other studies found that under steady-state conditions, the concentration of stable isotopes of soil moisture decreased exponentially with increasing depth. Additionally, other studies such as that of Broxton [13] established that the small watershed slope and the hydrological response of basins in the mountainous regions of New Mexico had generally different snow melting rates, evapotranspiration and water cycles. The author found that the isotopic variability and estimated concentration time were related to the orientations of the basins. Domestic scholars studied the isotopic composition of soil moisture later, but rapid advancements have been made in this field. Tian et al. [14] examined the precipitation and isotopic composition of soil moisture in the middle of the Qinghai Xizang Plateau and analyzed the regularities of stable isotopes and their association with water migration under different depths of the soil profile. Hou et al. [15] studied the stable isotopes characteristics of rainfall infiltration under vegetation composed of three typical species in Taihang Mountain. Deng et al. [16] using spring water stable isotopes variation analysis conducted research on the relationships between the transformations under low mountain precipitation of soil moisture of three areas in the Beijing Xishan Jiufeng region. Cheng and Liu [17] determined the levels of the stable isotopes of soil moisture under conditions of precipitation in a loess source region and four types of land use, and studied the characteristics of the stable isotopes of soil moisture and the mechanism of soil moisture movement in this area.

Nevertheless, the studies on the changes in the stable isotopes of deep soil moisture in the dry-hot valley region of Yuanmou, especially under the conditions of different land use types, are still scarce. In the present investigation, in the demonstration area of soil and water conservation in the old urban and rural areas of Yuanmou, we used the stable hydrogen and oxygen isotopes tracer technique and analyzed the stable isotopes in the soil profile at a depth of $0-100 \mathrm{~cm}$ in three land use types (Leucaena Benth artificial forest, Heteropogon contortus grass field, and farmland). We determined the characteristics of isotope profile distribution and the variations in soil moisture. And futher revealed the deep soil desiccation conditions. Furthermore, we established the mechanisms of formation and movement of soil moisture, as well as the water recharge mechanism. Our findings provide a reference for solving the issue of meeting the water needs of the dry-hot valley vegetation and facilitate vegetation restoration and meaningful water resources regulation.

\section{Materials and Methods}

\subsection{Overview of the characteristics of the study area}

This study area was a typical district in dry-hot valley of Yuanmou, with the following geographical coordinates:

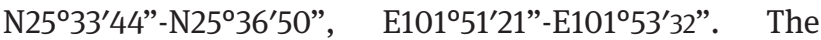
region is characterized by distinct dry and wet seasons, an average annual rainfall of more than $\leq 800 \mathrm{~mm}$, average annual temperature of $21.9^{\circ} \mathrm{C}, \geq 10^{\circ} \mathrm{C}$, and accumulated temperature of $7,791.6^{\circ} \mathrm{C}$. The average evaporation equals $3,847.8 \mathrm{~mm}$ while the average annual rainfall is only $634 \mathrm{~mm}$. More than 1.5 of the average annual of climatic dryness. Between $80 \%$ and $90 \%$ of the total rainfall in the whole year occurs in the period from June to October. The absolute maximum value of the temperature is above $40^{\circ} \mathrm{C}$. A small number of trees exist in shady sites with a thick soil layer. More herbaceous species are present here, and the vegetation is dominated by Heteropogon contortus, Enlariopsis binata, Cymbopogon matinii, Aristida adscensionis, and Bothriochloa pertusa, etc. The shrubs were dominated by Dodonaea angustifolia, Phyllanthus emblica, and Zizyphus yunnanensis, etc, whereas Leucaena Benth, Eucalyptus, and Acaciamangium are predominant among the tree species.

\subsection{Sample collection and method}

\subsubsection{Sampling method}

Three types of vegetation (Leucaena Benth artificial forest, Heteropogon contortus grass, and farmland) were selected for examinations in the dry-hot valley. Five positions were selected on each slope based on the altitude gradient from top to bottom, farmland set three slopes position, the 20 $\mathrm{m} \star 20 \mathrm{~m}$ fixed sample plots were at each slope. The soil drilling or the profile method was employed in June 2016 
Table 1: Basic features to different land use types.

\begin{tabular}{|c|c|c|c|c|c|c|c|c|}
\hline $\begin{array}{l}\text { Land use } \\
\text { types }\end{array}$ & $\begin{array}{l}\text { Geographical } \\
\text { coordinates }\end{array}$ & $\begin{array}{l}\text { Slope } \\
\left({ }^{\circ}\right)\end{array}$ & $\begin{array}{l}\text { Slope } \\
\text { direction }\end{array}$ & Altitude(m) & $\begin{array}{l}\text { Soil } \\
\text { types }\end{array}$ & $\begin{array}{l}\text { Vegetation } \\
\text { types }\end{array}$ & $\begin{array}{l}\text { Vegetation } \\
\text { coverage (\%) }\end{array}$ & $\begin{array}{l}\text { Soil moisture } \\
\text { content (\%) }\end{array}$ \\
\hline $\begin{array}{l}\text { Forest } \\
\text { land }\end{array}$ & $\begin{array}{l}\text { N25est landre } \\
\text { E101st landre }\end{array}$ & 19 & Southwest & 1,321 & $\begin{array}{l}\text { Dry red } \\
\text { soil }\end{array}$ & $\begin{array}{l}\text { Leucaena } \\
\text { Benth }\end{array}$ & 80 & 16.15 \\
\hline $\begin{array}{l}\text { Grass- } \\
\text { land }\end{array}$ & $\begin{array}{l}\text { N25sslandoile } \\
\text { E101slandoile }\end{array}$ & 25 & Northwest & 1,313 & $\begin{array}{l}\text { Dry red } \\
\text { soil }\end{array}$ & $\begin{array}{l}\text { Heteropogon } \\
\text { contortus }\end{array}$ & 85 & 14.63 \\
\hline Farmland & $\begin{array}{l}\text { N25mlandssn C } \\
\text { E101landssn ca }\end{array}$ & 12 & West & 1,278 & $\begin{array}{l}\text { Dry red } \\
\text { soil }\end{array}$ & $\begin{array}{l}\text { Corn, } \\
\text { Pumpkin }\end{array}$ & 90 & 17.47 \\
\hline
\end{tabular}

to collect soil samples from different depths in each of the predetermined plots (Table 1). The sampling depth was recorded for the areas occupied with Leucaena Benth artificial forest $(0-100 \mathrm{~cm})$, Heteropogon contortus grass $(0-100 \mathrm{~cm})$, and farmland $(0-60 \mathrm{~cm})$. A mixed sample collected at soil depth intervals of $20 \mathrm{~cm}$. To avoid the isotopes fractionation triggered by evaporation, samples were collected on the site and quickly transferred into 8-mL glass bottles and sealed, then put in a low-temperature sample box and transported to the laboratory for cry opreservation. To reduce the human disturbance in the course of sampling, the landfill of the same volume was adopted after the soil sample was collected. Soil moisture was measured by the drying method, which refers to the water expelled from the soil at $105^{\circ} \mathrm{C}$. Vacuum extraction of soil moisture and determination of the stable hydrogen and oxygen isotopes were accomplished at the central Stable Isotope Laboratory of China Academy of Forestry Sciences.

\subsubsection{Sample analysis}

Soil moisture content was determined by traditional drying-weighing methods. Soil moisture was extracted by low temperature vacuum distillation [18]. Compared with the azeotropic distillation method, this approach was more time-consuming, but the extracted water reflected more precisely the composition of hydrogen and oxygen isotopes in the sample [19]. In the extraction process, we ensured that the entire device was in a vacuum state without leakage and that the sample was no longer producing water vapor, indicating that the water had been fully pumped. The extracted soil moisture filtered by Picarro L2140-i micro-temperature cracking reaction module, with the majority of the organic contamination removes, was measured by Picarro L2130-i (Picarro, Inc., Sunnyvale, CA, USA) ultra-high-precision liquid water and water vapor isotopes analyzer of hydrogen and oxygen isotopes, the errors were less than $0.100 \%$ and $0.025 \%$. The analysis results in isotopes of hydrogen and oxygen with levels that are thousand points lower than the Standard Mean Ocean Water (SMOW).

$$
\delta \mathrm{X}=\left[\mathrm{R}_{\mathrm{sam}} / \mathrm{R}_{\mathrm{std}}-1\right] \times 1000
$$

Where: $\mathrm{R}_{\mathrm{sam}}=$ the natural abundance ratio of hydrogen or oxygen isotopes in the sample tested ( $\% 0)$; $R_{\text {std }}=$ the natural abundance ratio of the hydrogen or oxygen isotopes of the Standard Mean Ocean Water (SMOW) (\%o)

\subsubsection{Data analysis}

The correlation between hydrogen and oxygen isotopes of soil moisture in different soil layers under different land use types were analyzed statistically by SPSS. The transforms of hydrogen and oxygen isotopes of soil moisture in different soil layers under different land use types were plotted using SigmaPlot 10.0 and Microsoft Excel 2010.

Ethical approval: The conducted research is not related to either human or animal use.

\section{Results}

\subsection{Characteristics of soil mechanical composition}

The mechanical composition of coarse silt the soil under different land use types in Yuanmou about $40 \%$ of each layer, which is the main component of the sample. The weight percentage of the fine sand was less than $20 \%$ per layer, and that of sand accounted for less than $10 \%$ in all forest layers, whereas it as approximately $20 \%$ in all layers of the grassland soil. Therefore, we determined the soil in 
Table 2: Soil mechanical composition by soil depth under the different land use types.

\begin{tabular}{|c|c|c|c|c|c|c|}
\hline \multirow[t]{2}{*}{ Land use types } & \multirow[t]{2}{*}{ Soil layer $(\mathrm{cm})$} & \multicolumn{5}{|c|}{ The mass percentage of each grade particle size (\%) } \\
\hline & & $\begin{array}{l}\text { Clay } \\
(<0.001 \mathrm{~mm})\end{array}$ & $\begin{array}{l}\text { Fine sand } \\
(0.001-0.005 \mathrm{~mm})\end{array}$ & $\begin{array}{l}\text { Medium silt } \\
(0.005-0.01 \mathrm{~mm})\end{array}$ & $\begin{array}{l}\text { Coarse silt } \\
(0.01-0.05 \mathrm{~mm})\end{array}$ & $\begin{array}{l}\text { Sand } \\
(>0.05 \mathrm{~mm})\end{array}$ \\
\hline \multirow[t]{5}{*}{ Forest land } & $0-20$ & 8.7 & 17.6 & 21.5 & 44.0 & 8.3 \\
\hline & $20-40$ & 8.7 & 13.1 & 23.4 & 47.5 & 7.3 \\
\hline & $40-60$ & 8.0 & 12.8 & 27.2 & 46.9 & 5.1 \\
\hline & $60-80$ & 9.9 & 15.6 & 34.1 & 35.9 & 4.5 \\
\hline & $80-100$ & 15.9 & 12.3 & 29.8 & 32.6 & 9.4 \\
\hline \multirow[t]{5}{*}{ Grassland } & $0-20$ & 10.0 & 9.8 & 29.0 & 37.3 & 14.0 \\
\hline & $20-40$ & 7.2 & 5.4 & 23.5 & 39.8 & 24.0 \\
\hline & $40-60$ & 6.5 & 5.7 & 21.7 & 37.4 & 28.8 \\
\hline & $60-80$ & 8.5 & 7.0 & 27.0 & 37.7 & 19.8 \\
\hline & $80-100$ & 6.7 & 5.6 & 26.5 & 41.3 & 20.0 \\
\hline \multirow[t]{2}{*}{ Farmland } & $0-20$ & 10.7 & 17.3 & 29.4 & 37.8 & 4.8 \\
\hline & $20-40$ & 14.4 & 19.2 & 32.7 & 28.8 & 5.0 \\
\hline
\end{tabular}

the soil profile $0-100 \mathrm{~cm}$ of the dry hot valley in Yuanmou as coarse sandy loam (Table 2).

\subsection{Dynamics of the soil moisture content}

In a previous study, the soil moisture content directly affected the ratios of soil solid and liquid components, and the gas three-phase ratio, as well as soil fertility and crop growth and development [20]. In our investigation, the soil moisture content had different dynamic characteristics under different land use types (Fig. 1). The soil moisture content established could be arranged in the following descending order: sloping farmland $(17.47 \%)>$ forest land $(16.15 \%)>$ grassland $(14.63 \%)$. The main reason for this arrangement can be attributed to the increase in the artificial water content of the soil by the drip irrigation applied in the farmland, leading to its highest soil moisture content values. On the other hand the higher moisture amount in the forest land than that of the grassland was due to the thicker canopy and denser foliage, and the forest owing to which that land received the total amount of solar radiation than the grassland was smaller, coupled with the surface of more litter cover, soil evaporation was small, so the forest land soil moisture content was higher. The soil layer of the forest land had the lowest moisture content at a depth of $60-80 \mathrm{~cm}$, whereas the soil layer $40-60 \mathrm{~cm}$ of the grassland exhibited its lowest moisture amount. Above $60 \mathrm{~cm}$ soil layer, the content soil moisture of each of the three land use types decreased

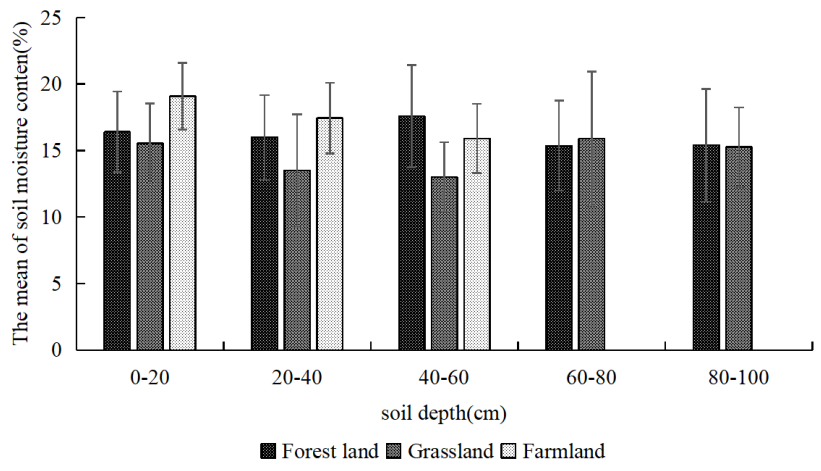

Figure 1: Characteristics of the soil moisture under different land use types at the studied soil depths.

with the increase of soil depth. Below the $60 \mathrm{~cm}$ soil layer, the content soil moisture of the forest land increased with the depth of the soil layer, while the grassland increased first and then decreased with the increase of depth. This was mainly due to differences among the soil moisture consumption of different vegetations. The variable coefficient of soil moisture at three land use types was moderate intensity, which showed grassland $>$ forest land $>$ farmland.

\subsection{Dynamics of hydrogen and oxygen isotopic composition of soil moisture}

The changing range of hydrogen and oxygen isotopes composition of soil moisture was as follows: forest land 


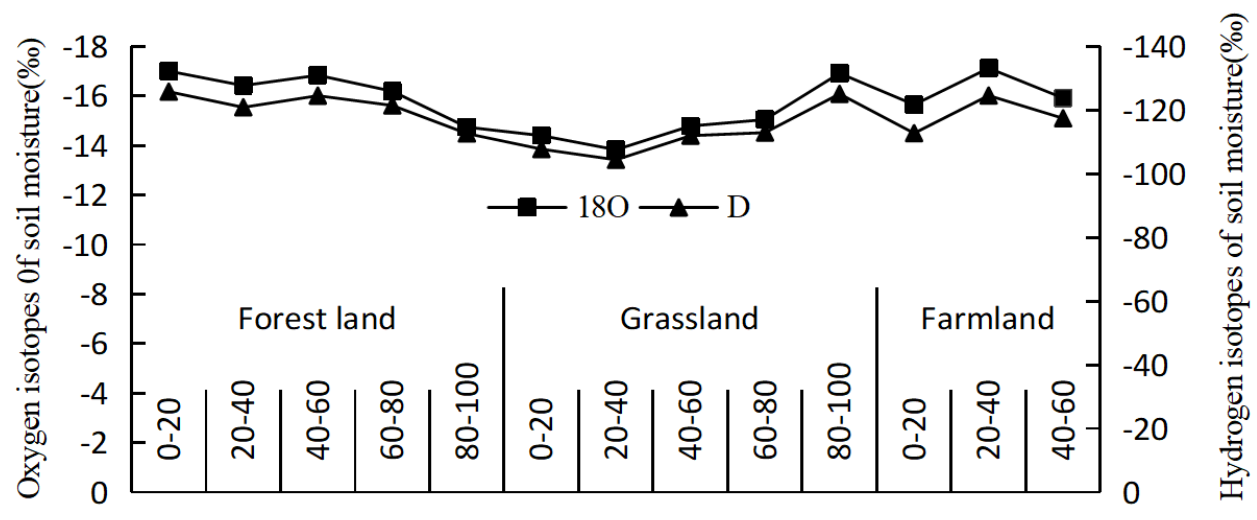

Soil depth(cm)

Figure 2: Composition of hydrogen and oxygen isotopes of soil moisture under different land use types and soil depths.

$(-146.36 \% 0)-(-84.26 \% 0)$ and $(-20.06 \%)-(-10.32 \% 0)$, the average value was $-121.12 \%$ and $-16.25 \%$. Grassland $(-146.05 \% 0)-(-91.90 \% 0)$ and $(-20.27 \% 0)-(-12.08 \% 0)$, the average value was $-112.49 \%$ and $-15.00 \%$, farmland $(-147.70 \% 0)-(-100.79 \% 0)$ and $(-20.20 \% 0)-(-13.09 \% 0)$, the average values were $118.53 \%$ and $-16.28 \%$. The hydrogen and oxygen isotopes in the soil moisture varied significantly with the increase in depth of the soil layer, and the trends of the variations in the hydrogen and oxygen isotopes in the soil moisture were basically identical. Due to presence of stable hydrogen and oxygen isotopes in the soil moisture, they obeyed the same transformation law, and the molecular weight of the hydrogen isotopes was lower than that of the oxygen isotopes. Thus, the fractionation effect of the hydrogen isotopes was stronger than that of the oxygen isotopes. Therefore, it is more convincing to use the change of hydrogen isotopes to interpret the movement of soil moisture, which is also the reason why the application of hydrogen isotopes is more extensive than that of oxygen isotopes.

\subsubsection{Properties of hydrogen and oxygen isotopes in the soil moisture under different land use types at various depths of the soil layer}

The isotopes ratios of soil moisture (Figure 2) varied depending on the different land use types and by soil depth on the slopes of the forest land and the grassland, and considerable changes were observed at $20-40 \mathrm{~cm}$ in the layers of the upper and middle slopes. The stable isotopes reached its maximum value in the forest soil, and the grassland in the $80-100 \mathrm{~cm}$ soil layer reached a maximum value that was significantly greater than that of the forest. In the lower part of the slope, the changes in the soils under the three land use types were small, with no obvious trends. No significant changes were observed also in the ratios of the stable isotopes in different slope positions of the farmland. This approach is one of the few that permit an assessment of the amount of deep water percolation, in cases of absence of water content change in deeper layers. As is well known, according to the principles of soil physics, the process of deep water percolation is realized by two ways: increase in the water reserve in the deeper layers and without a change in the soil moisture in those layers. The stable isotopes method can be used to analyze the change in the water content in the soil layers, and then the depth of water penetration can be evaluated.

\subsubsection{Statistical characteristics of hydrogen isotopes in the soil moisture under different land use types with the depth of soil layer}

The hydrogen isotopes of soil moisture in different soil layers under different land use types were analyzed by descriptive statistics. As can be seen from Table 3, although the hydrogen isotopes in soil moisture were affected by the land use types, precipitation infiltration and evaporation increased with the soil depth. The mean values can be arranged in the following descending order of the hydrogen isotopes in the soil layer in the forest land was: $80-100 \mathrm{~cm}>20-40 \mathrm{~cm}>60-80 \mathrm{~cm}>40-60 \mathrm{~cm}>0-20$ $\mathrm{cm}$. Hence, the upper layer of the soil moisture was "light", whereas the lower-layer soil moisture characterized it as "heavy". The soil moisture in the upper depths was more considerably affected by rainfall, so the soil moisture 
Table 3: Statistical characteristics of the hydrogen isotopes in soil moisture of different land use types and soil depth.

\begin{tabular}{llllll}
\hline Land use types & Soil layer(cm) & Minimum (\%) & Maximum (\%) & Mean (\%) & Coefficient of variation \\
\hline Forest land & $0-20$ & -139.1 & -107.5 & -125.8 & 0.1 \\
& $20-40$ & -141.1 & -92.5 & -120.9 & 0.2 \\
& $40-60$ & -146.4 & -95.6 & -124.6 & 0.2 \\
& $60-80$ & -141.5 & -101.2 & -121.5 & 0.1 \\
& $80-100$ & -135.0 & -84.3 & -112.7 & 0.2 \\
Grassland & $0-20$ & -129.4 & -98.0 & -107.8 & 0.1 \\
& $20-40$ & -122.7 & -91.9 & -104.5 & 0.1 \\
& $40-60$ & -124.5 & -94.1 & -112.0 & 0.1 \\
& $60-80$ & -125.3 & -99.5 & -113.0 & 0.1 \\
& $80-100$ & -146.0 & -100.8 & -125.2 & 0.2 \\
Farmland & $0-20$ & -141.1 & -102.2 & -113.5 & 0.1 \\
& $20-40$ & -145.6 & -112.9 & -124.6 & 0.1 \\
& $40-60$ & -147.7 & -100.8 & -117.5 & 0.1 \\
\hline
\end{tabular}

"light", the lower rainfall impact weakened, so the soil moisture was "heavy". The mean value of the hydrogen isotopes in soil moisture at grassland was: $20-40 \mathrm{~cm}$ > $0-20 \mathrm{~cm}$, below $40 \mathrm{~cm}$. The mean values of the hydrogen isotopes displayed a decreasing trend with the increase of soil depth. The mean value of the hydrogen isotopes in the soil moisture layer in the farmland could be arranged in the descending order: $0-20 \mathrm{~cm}>40-60 \mathrm{~cm}>20-40 \mathrm{~cm}$.

The variable coefficient of reflected the changing degree of hydrogen isotopes in soil moisture at different depths. The greater variable coefficient of indicated more intense transformation of the hydrogen isotopes in soil moisture, and vice versa [21]. The variable coefficient of hydrogen isotopes in the forest land was the lowest in the 0-20 cm soil layer, and the below $20 \mathrm{~cm}$ decreased along the depth, so it had the greatest variability. The variable coefficient of the hydrogen isotopes of the grassland was the largest in 80-100 $\mathrm{cm}$ soil layer, because of that the hydrogen isotopes was continuously enriched by evaporation fractionation, which changed the hydrogen isotopes of soil moisture in this layer. Over the $80 \mathrm{~cm}$ soil layers, it decreased with the increase of soil depth, which was the smallest in $60-80 \mathrm{~cm}$ soil layer. It indicated that evaporation of soil was weak, of which had better water retention effect in $60-80 \mathrm{~cm}$. The variation was large, due to strong soil evaporation in $0-20 \mathrm{~cm}$ soil layer. The variable coefficient of hydrogen isotopes of different layers showed $0-20 \mathrm{~cm}>40-60 \mathrm{~cm}>20-40 \mathrm{~cm}$ in farmland. Because of man-made irrigation and rainfall, the soil varied most in $0-20 \mathrm{~cm}$. The soil moisture retained the isotopic characteristics of groundwater to the maximum extent, and it depended less on evaporation in $20-40 \mathrm{~cm}$ soil layer.

The contents of hydrogen isotopes varied considerably in the soil surface under the three land use types studied (Figure 3), but was constant in the deep soil layer. This tendency was due to the susceptibility of the shallow soil moisture to precipitation mixture and evaporation, leading to substantial variations in the quantities of hydrogen isotopes. While the deep soil moisture receiving precipitation was limited, so its value transformed little. Among them, forest land and grassland were above the 60 $\mathrm{cm}$ soil layers, the fluctuation range were most apparent. The fluctuations in the range of hydrogen isotopes in the surface layer of $0-20 \mathrm{~cm}$ in the farmland area were the largest. In general, at a soil depth of $60-100 \mathrm{~cm}$, the levels hydrogen isotopes of soil moisture in the forest land and grassland recovered and stabilized their rates, indicating that evaporation exerted an insignificant influence on the levels of hydrogen isotopes in deep soil moisture.

\subsubsection{Relationship between hydrogen and oxygen isotopes in soil moisture under different land use types}

Regression analysis was conducted to evaluate the correlation between the hydrogen and oxygen isotopes of 


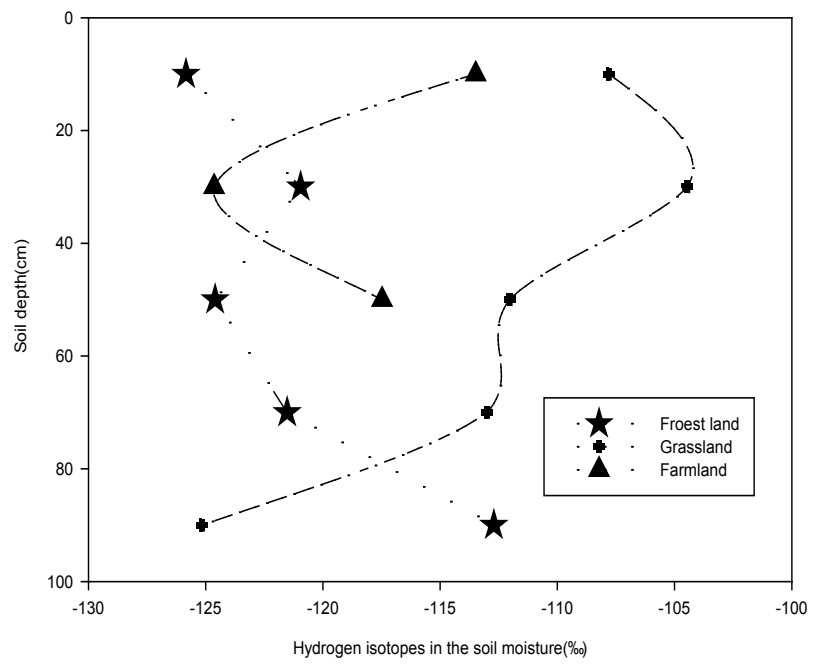

Figure 3: Vertical variations of hydrogen isotopes in the soil moisture under different land use types.

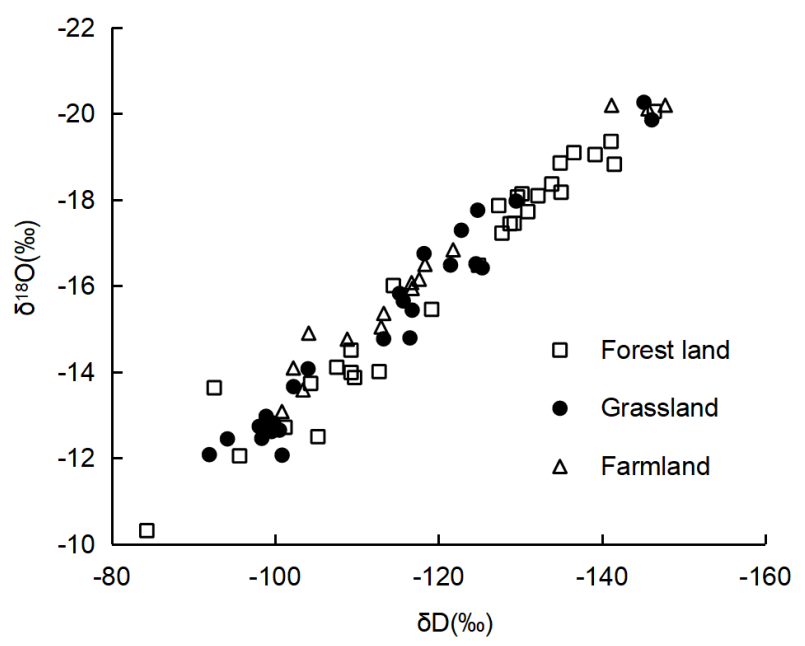

Figure 4: Relationship between the hydrogen and oxygen isotopes of soil moisture under different land use types.

soil moisture under three different land use types (Figure4). The corresponding equations obtained are as follows:

Forest land: $\mathrm{D}_{\mathrm{fl}}=6.067^{18} \mathrm{O}_{\mathrm{fl}}-22.558\left(\mathrm{R}^{2}=0.976, \mathrm{n}=25\right)$, Grassland: $\mathrm{D}_{\mathrm{g}}=6.024^{18} \mathrm{O}_{\mathrm{g}}-22.134\left(\mathrm{R}^{2}=0.980, \mathrm{n}=25\right)$, Farmland: $\mathrm{D}_{\mathrm{f}}=6.549^{18} \mathrm{O}_{\mathrm{f}}-11.991\left(\mathrm{R}^{2}=0.987, \mathrm{n}=15\right)$.

The evaporation, composed of hydrogen and oxygen isotopes in soil moisture, is a function of humidity that could reflect the degree of evaporation experienced by water bodies [22]. In our study, the magnitude of intercepts and slopes indicated the extent of evaporation and fractionation since the field was located in a semiarid area with low humidity and strong evaporation, and the slope was smaller. The transformation of the hydrogen and oxygen isotopes of soil moisture was affected by many factors, such as stable isotopes in atmospheric precipitation, surface evaporation, horizontal migration, and the vertical movement of moisture in soil, as well as land use types and human activities [23]. The site conditions of the forest land and grassland in the study area of the present investigation were more complicated than that of farmland, and the vegetation types were more diverse, whereas the site conditions and crop types grown in the farmland were relatively simple.

\section{Discussion}

The soil moisture content is the link between the atmospheric and plant water in the soil-plant-atmosphere continuum systems. In the course of the vertical movement of soil moisture, evaporation of water occurs. The hydrogen and oxygen isotopes of soil moisture can reflect the characteristics of soil moisture movement, and their changes are closely influenced by land use types, water vapor sources, meteorological conditions, atmospheric circulation, and other factors. The influence of land use types on soil moisture is especially complex and can hinder the direct action of precipitation on soil and affect the evaporation of soil moisture by creating a distinct local microclimate. Furthermore, the litter layer can prevent precipitation from striking the soil, and thus indirectly influences the infiltration process by improving soil properties. On the one hand, the underground part can cause changes in soil properties, such as an increase in soil porosity and soil moisture holding capacity, and an improvement of water retention characteristics. On the other hand, plant roots can also indirectly affect the distribution of soil moisture through the absorption and utilization of soil moisture [24]. Therefore, studying the dynamic variations of hydrogen and oxygen isotopes profile of soil moisture is vital to better understanding the mechanisms of water movement, precipitation infiltration recharges, evaporation of soil moisture, and water uptake by plant roots in a SPAC system. At the same time, research on the relationships between hydrogen and oxygen isotopes in soil moisture and the vertical changes in soil profile, lay the foundation for exploring plant root water absorption [25-27]. The evapotranspiration of plants and the hydraulic enhancement of roots lead to dynamic changes of hydrogen and oxygen isotopes in soil moisture across the soil profile. In an earlier examination, when water was absorbed by plant roots and moved from 
the roots to the leaves, isotopes fractionation was not usually observed, but the concentration of hydrogen and oxygen isotopes in soil moisture changed [28]. Vertical variations of hydrogen and oxygen isotopes in soil moisture throughout the soil profile resulted mainly from the actions of surface evaporation conditions and the varying root depth expanding across different soil levels under diverse land use types. Because of the difference in soil texture and structure, the characteristics of the soil layers at different depths may affect the infiltration, recharge from rainfall, and the behavior of plant roots [29]. However, the changes of hydrogen and oxygen isotopes in deep soil moisture displayed a lag, and the range of their alterations was relatively small. Especially in arid and semi-arid areas [30], plant transpiration is more likely to lead to an enrichment of hydrogen and oxygen isotopes of soil moisture.

In this study, soil depth was the main factor affecting the hydrogen and oxygen isotopes of soil moisture. With the increasing of soil depth, the water transport process was retarded, and over $60 \mathrm{~cm}$ was the active area. At that depth, the soil structure was loose, and water infiltration was faster. Besides, there was a strong exchange of moisture vapor in the soil layer, which means that the evaporation of precipitation could have a strong effect on surface soil moisture. In addition, soil surface mulch might have had a considerable influence on the soil physical environment near the surface, especially when the soil depth was more than $60 \mathrm{~cm}$; different mulch materials varied in their capacity to suppress soil moisture evaporation [31]. Previous studies [32-34] have shown that different land use types may have a substantial impact on the soil physical environment near the surface, especially at a soil depth of more than $60 \mathrm{~cm}$. Thus, the inhibition intensity of soil moisture evaporation is different. In general, the variation trend of hydrogen isotopes value of soil moisture was dissimilar from that of deep soil moisture under different land use types. Moreover, deep-level soil moisture was interrupted by outside interference extremely weakly, reverse from the surfer layer soil. And it indicated that surfer layer soil had stronger water permeability and less water retention in the process of infiltration. For forest land and grassland, the hydrogen isotope in deep-level soil moisture was higher than that in the surface layer, reverse from the farmland, which reflected the isotopes fractionation effect of soil evaporation to some extent.

The vertical distribution of soil moisture refers to the transformation of soil moisture with the depth of a soil layer, which is affected by precipitation and root absorption. In an earlier investigation, the authors found that the vertical distribution of soil moisture across the soil profile was uneven under different land use types [35]. On the same slope, the differences in the position, land use type, plant growth status, and the soil physical and chemical properties also led to variations in soil moisture distribution. The variation of the hydrogen isotopes in soil moisture with soil depth had the following characteristics. First, under different land use types, the hydrogen isotopes of soil moisture were different in the upper soil layer but tended to be consistent with increased with the increase in soil depth. The hydrogen isotopes of the forest land initially increased with the depth, then decreased and increased again. Nevertheless, generally, the trend was increasing, and the maximum value appeared within $80-100 \mathrm{~cm}$, that is, in the deep soil layer. The hydrogen isotopes value of the grassland first increased with depth, similarly to that the trend in the forest land, but then continuously decreased, and their maximum value appeared in the range $20-40 \mathrm{~cm}$. The hydrogen isotopes value of soil moisture of the farmland increased more with the depth of the soil layer, as compared with the forest land and grassland, which showed an opposite association. Second, under the same land use type, the values of the hydrogen isotopes of soil moisture in the upper soil layer changed drastically with the increasing of depth, and the level of hydrogen isotopes decreased significantly. With the increase in soil depth, the fluctuations in the values of the hydrogen and oxygen isotopes of soil moisture gradually diminished. This tendency was particularly obvious for the soil depth of $80-100 \mathrm{~cm}$, where the levels of hydrogen and oxygen isotopes of soil moisture were stable. The moisture content in the soil surface was easily influenced by the combined impact of atmospheric precipitation and evaporation. This combined activities resulted in substantial transformation in the composition of hydrogen and oxygen isotopes. Nevertheless, the compensation of atmospheric precipitation for deep soil moisture was exceedingly limited, leading to minor changes in the composition of its hydrogen and oxygen isotopic values. Under different land use types, the values of the hydrogen and oxygen isotopes of soil moisture were different and tended to ascending with the increase in depth. Under the same land use type, the change of hydrogen and oxygen isotopes values of soil moisture was not apparent. This finding indicated that the mechanisms of water infiltration under different land use types were different. Studies have showed that the large pore preferential flow may be the only channel for resources of deep-level soil moisture [36]. The variation of hydrogen and oxygen isotopes of soil moisture affected by many factors, such as the hydrogen and oxygen isotopes of atmospheric precipitation, surface evaporation, horizontal migration and vertical movement 
of soil moisture, as well as vegetation types and human activities [37]. The presence of preferential flow in soils under different vegetation cover is well known. From the view of regularities of water movement, the quantitative regularities of soil water balance under different vegetation cover in the rainfall condition were explained by the data on the isotopes distribution of the soil profiles in this study. Furthermore, after analysed of rainwater infiltration into the soil, a part of evapotranspiration was released, and the other part was retained in the root zone and penetrated deeper. Therefore, the changes of hydrogen and oxygen isotopes in soil moisture of the deep layers of forest land and grassland confirmed that a preferential flow occurs during the process of precipitation infiltration. Because of the well-developed root system of the plants inhabiting the forest land and the grassland, conditions for the formation of large pores existed, and the necessary path for the generation of a preferential flow. was also provided In the farmland, due to the influence of the vegetation coverage and human disturbance, the degree of soil compaction was considerable, less large pores were available. Furthermore, this slowed down the infiltration velocity resulting in an infiltration process that was mainly in the form of a piston flow and an isotopic enrichment of the soil surface. The hydrogen and oxygen isotopes of soil moisture had a good linear relationship during the sampling period. No significant differences in the hydrogen and oxygen isotopic content of soil moisture were observed among the three land use types. Additionally, the gradient was distributed with depth. An earlier study showed that the values of hydrogen isotopes of soil moisture were also associated with rainfall [38]. Furthermore, in addition to the effects of precipitation, hydrogen isotopes were also affected by the exchange of water and surface evaporation [39]. In addition, land use type is a vital factor affecting the underlying surface of the watershed. Vegetation can affect evaporation and emission, as well as surface runoff and soil erosion, through different physiological characteristics [40]. The enrichment of hydrogen and oxygen isotopic in the soil moisture in the Leucaena Benth artificial forest and Heteropogon contortus grass field were similar. The reason for that similarity was that the canopy interception and the influence on precipitation infiltration were not only superimposed, but also slightly different. The diverse land use types exerted various inhibiting intensities on soil moisture evaporation. For example, the canopy interception of the Leucaena Benth artificial forest was stronger than that of the Heteropogon contortus grass field. These dissimilarity led to more significant precipitation evaporation fractionation in the Leucaena Benth artificial forest, but its soil infiltration rate was higher, which further reduced the fractionation of the soil moisture infiltration process. Therefore, the extent of enrichment of the hydrogen and oxygen isotopic content in soil moisture was similar. These processes in the farmland were affected by human disturbance, which resulted in a more distinct change. In the different land use types, the characteristics of the migration of hydrogen and oxygen isotopes in the soil moisture and their mechanism of migration were successfully studied in preceding research [41]. Nevertheless, water resources issues, such as ecological water demand, water cycle, and vegetation restoration in the dry hot valley region of Yuanmou have not yet been resolved until now. Therefore, further continuous and comprehensive research in this area is required to elucidate the underlying mechanisms and provide an appropriate solution of this critical problem under the ever-increasing negative impact of global warming.

\section{Conclusion}

We found a close relationship between soil texture and effective water capacity in the soil at 0-100 $\mathrm{cm}$, which we characterized as coarse sandy loam. The content of soil moisture showed different levels of dynamic transformation under the different land use types. The soil moisture percentage can be arranged in the following descending order: sloping farmland $(17.47 \%)>$ forest land $(16.15 \%)>$ grassland $(14.63 \%)$. The average values of hydrogen and oxygen isotopes in the composition of soil moisture were as follows: forest land (-121.12\%o) and $(-16.25 \% 0)$, grassland $(-112.49 \% 0)$ and $(-15.00 \% 0)$, and farmland $(118.53 \% 0)$ and $(-16.28 \% 0)$, respectively. The precipitation and evaporation were vital factors in controlling the transformation of hydrogen and oxygen isotopes composition of soil moisture. The variable coefficient of hydrogen isotopes in the forest land was the lowest in the $0-20 \mathrm{~cm}$ soil layers, whereas it decreased in the soil layers below $20 \mathrm{~cm}$ with the increase in soil depth. The grassland was the largest in the $80-100 \mathrm{~cm}$ soil layer, 80 $\mathrm{cm}$ above decreased with the depth. The soil at the depth $0-20 \mathrm{~cm}$ in the farmland exhibited the greatest variability that was due to anthropogenic drip irrigation disturbance and rainfall. The order here was $0-20 \mathrm{~cm}>40-60 \mathrm{~cm}$ $>20-40 \mathrm{~cm}$. The values of the hydrogen isotopes of soil moisture varied significantly and generally consistently with the depth of the soil layers. We established the following major tendencies. First, different levels of the hydrogen isotopes of soil moisture in the upper soil layer 
were observed under different land use types. As for the forest land increased first, then decreased and then increased, and the maximum value appeared in 80-100 $\mathrm{cm}$. And in grassland increased first, but then decreased continuously, so the maximum value appeared in the range $20-40 \mathrm{~cm}$. And in farmland it began to decrease and then increased with the increasing of depth. Second, under the same land use type, the hydrogen isotopes value of soil moisture in the upper soil layer changed drastically, With the increasing of depth, the trend is obviously decreasing.

Acknowledgments: This work was supported by the National Natural Science Foundation of China (Project No.31860235, 31760149, 31560233) . Fund to Key Research and Development Program of Yunnan Provincial Science and Technology Department(No.2018BB018); Fund Project to The forestry science and technology innovation platform project of The State Forestry Administration (2018-LYPT-DW-162; 2018-YN-12); Fund Project to the Innovative Training Program for Provincial College Students (S201710677014)

Conflict of interest: The authors declare they have no conflict of interest.

\section{References}

[1] Thevs N., Ovezmuradov K., Zanjani L.V., Zerbe S., Water consumption of agriculture and natural ecosystems at the Amu Darya in Lebap Province, Turkmenistan, Environmental Earth Sciences, 2015, 73(2), 731-741.

[2] Jiao Y.L., Li R., Zhao L., Xiao Y., Hu G.J., Qiao Y.P., Processes of soil thawing-freezing and features of soil moisture migration in the permafrost active layer, Journal of Glaciolog and Geocryology, 2014, 36(2), 237-247.

[3] Wang Z.H., A new perspective of urban-rural differences: The impact of soil moisture advection, Urban Climate, 2014, 10, 19-34.

[4] Chen T.T., Chen H., Han L., Xing X., Fu Y.Y., Stable isotopes characters of soil water movement in Shijiazhuang City, Environmental Science, 2015, 36(10), 3641-3648.

[5] Koeniger P., Leibundgut C., Link T., Marshall J.D., Stable isotopes applied as water tracers in column and field studies, Organic Geochemistry, 2010, 41(1), 31-40.

[6] Liu J., Wei W., Zhang L., Wang Y., Duan B.Q., Liu F.L., Application on isotopes $D$ and ${ }^{18} \mathrm{O}$ of soil water in water movement of unsaturated zone, Investigation Science and Technology, 2012, (5), 38-43.

[7] Zhang X.J., Song W.F., Wu J.K., Wang Z.J., Characteristics of hydrogen and oxygen isotopes of soil water in the water source area of Yuanyang Terrace, Environmental Science, 2015, (6), 2102-2108.
[8] Rau G.C., Andersen M.S., Mccallum A.M., Acworth R.I., Analytical methods that use natural heat as a tracer to quantify surface water-groundwater exchange, evaluated using field temperature records, Hydrogeology Journal, 2010, 18(5), 10931110.

[9] Pang Z.H., Yuan L.J., Huang T.M., Kong Y.L., Liu J.L., Li Y.M., Impacts of human activities on the occurrence of groundwater nitrate in an alluvial plain: A multiple isotopic tracers approach, Journal of Earth Science, 2013, 24(1), 111-124.

[10] Hendry M.J., Wassenaar L.I., Millennial-scale diffusive migration of solutes in thick clay-rich aquitards: Evidence from multiple environmental tracers, Hydrogeology Journal, 2011, 19(1), 259270.

[11] Dansgaard W., The abundance of ${ }^{18} \mathrm{O}$ in atmospheric water and water vapor, Tellus, 1953, 5(4), 461-469.

[12] Schwen A., Zimmermann M., Bodner G., Vertical variations of soil hydraulic properties within two soil profiles and its relevance for soil water simulations, Journal of Hydrology, 2014, 516, 169-181.

[13] Broxton P.D., Troch P.A., Lyon S.W., On the role of aspect to quantify water transit times in small mountainous catchments, Water Resources Research, 2009, 45(8), 2263-2289.

[14] Tian L.D., Yao T.D., Sun W.Z., Atusi N., Toshio K., Stable isotopes variation of precipitation in the middle of Qinghai-Xizang Plateau and monsoon activity, Geochimica, 2001, 141(7), 17231729.

[15] Hou S.B., Song X.F., Yu J.J., Liu X., Zhang G.Y., Stable isotopes characters in the process of precipitation and infiltration in Taihang Mountainous Region, Resources Science, 2008, 30(1), 86-92.

[16] Deng W.P., Yu X.X., Jia G.D., Li Y.J., Liu Y.J., An analysis of characteristics of hydrogen and oxygen stable isotopes in Jiufeng Mountain areas of Beijing, Advances in Water Science, 2013, 24(5), 642-650.

[17] Cheng L.P., Liu W.Z., Characteristics of stable isotopes in soil moisture under several typical land use patterns on Loess Tableland, Chinese Journal of Applied Ecology, 2012, 23(3), 651658.

[18] Ding Y.L., Chen H.S., Yang J., Nie Y.P., Wang K.L., The shortest time of plant stem water extraction based on hydrogen and oxygen isotope analysis, Chinese Journal of Ecology, 2014, 33(4), 1004-1009.

[19] West A.G., Patrickson S.J., Ehleringer J.R., Water extraction times for plant and soil materials used in stable isotopes analysis, Rapid Communications in Mass Spectrometry: RCM, 2006, 20(8), 1317-1321.

[20] Tian R.C., Chen H.S., Song X.F., Wang K.L., Yang Q.Q., Meng W., Characteristics of soil water movement using stable isotopes in red soil Hilly region of Northwest Hunan, Environmental Science, 2009, 30(9), 2747-2754.

[21] Feakins S.J., Bentley L.P., Salinas N., Shenkin A., Blonder B., Goldsmith G.R., et al., Plant leaf wax biomarkers capture gradients in hydrogen isotopes of precipitation from the Andes and Amazon, Geochimica Et Cosmochimica Acta, 2016, 182, 155172.

[22] Gorski G., Strong C., Good S.P., Bares R., Ehleringer J.R., Bowen G.J., Vapor hydrogen and oxygen isotopes reflect water of combustion in the urban atmosphere, Proceedings of the National Academy of Sciences of the United States of America, 2015, 112(11), 3247-3252. 
Wu R.J., Xing X.Y., Variation characteristics and influencing factors of actual evapotranspiration under various vegetation types: $A$ case study in the Huaihe River Basin, China, Chinese Journal of Applied Ecology, 2016, 27(6), 1727-1736.

Zhou H., Zhao W.Z., Response of soil moisture to precipitation pulse by stable isotope in desert area of the Hexi Corridor, Journal of Desert Research, 2016, 36(6), 1637-1645.

[25] Chen M.L., Zhang B.W., Ren T.T., Wang S.S., Chen S.P., Responses of soil moisture to precipitation pattern change in semiarid grasslands in Nei Mongol, China, Chinese Journal of Plant Ecology, 2016, 40(7), 658-668.

[26] Wang L., Wei S.P., Zhang Q.F., Wang Q.J., Li S.Q., Isotopic characteristics of water within the soil-vegetation-atmosphere system in the Yushenfu mining area, Journal of China Coal Society, 2010, 35(8), 1347-1353.

[27] Xu Q., Liu S.R, Wan X.C, Jiang C.Q., Song X.F., Wang J.X., Effects of rainfall on soil moisture and water movement in a subalpine dark coniferous forest in southwestern China, Hydrological Processes, 2012, 26(25), 3800-3809.

[28] Zhang T.G., Li Z.B., Li P., Xu G.C., Liu X.J., Jin Y.R., Response characteristics of soil moisture use patterns by different plants to precipitation in rocky mountain areas, Chinese Journal of Applied Ecology, 2016, 27(5), 1461-1467.

[29] Wu J.E., Liu W.J., Zhu C.J., Application of stable isotopes techniques in the study of plant water sources and use efficiency, Journal of Southwest Forestry University, 2014, 34(5), 103-110.

[30] Yan D.F., Wang D.C., Yang X.T., Effects of surface root system on soil infiltration at different vegetation types in Danjiangkou Reservoir area, Science of Soil and Water Conservation, 2016, 14(3), 35-44.

[31] Wu H.W., Li X.Y., Jiang Z.Y., Li J., Zheng X.R., Zhao D.Z., Variations in water use for Achnatherum splendens in Lake Qinghai watershed based on $\delta D$ and $\delta^{18} 0$, Acta Ecologica Sinica, 2015, 35(24), 8174-8183.

[32] Miao L., Dong J.G., Wang Y.K., Jiang G.T., Soil water in deep layers under different land use patterns in the Loess Hilly and Gully region, Research of Soil and Water Conservation, 2016, 23(2), 13-18.

[33] Zheng X.R., Zhao G.Q., Li X.Y., Li L., Wu H.W., Zhang S.Y., et al., Application of stable hydrogen isotope in study of water sources for Caragana microphylla bushland in Nei Mongol, Chinese Journal of Plant Ecology, 2015, 39(2), 184-196.

[34] Hao H.M., Ren Z.Y., Xue L., Jiang Y.F., Quantitative study on response of ecosystem to land use/cover changes in Yulin area based on 35 technology, Progress in Geography, 2007, 26(3), 96-106.

[35] Lan Z.L., Pan X.L., Zhan Y., Si B.C., Wang Y.K., Jiao R., et al., Effects of land use types on deep soil water content in the loess hilly area of the north Shaanxi Province, China, Chinese Journal of Applied Ecology, 2017, 28(3), 847-855.

[36] Cheng L.P., Liu W.Z., Li Z., Han X.Y., Land use change affects groundwater recharge in the Changwu Loess Tableland of China, Advances in Water Science, 2016, 27(5), 670-678.

[37] Zhu L., Stable isotope hydrology process research in Puzhehei peak forest-lake basin, MSc thesis, Yunnan Normal University, Kunming, Yunnan, 2016.

[38] Wang R., Liu W.Z., Song X.F., Study on soil water dynamics on Loess Tableland based on stable hydrogen and oxygen isotopes, Journal of Soil and Water Conservation, 2014, 28(3), 134-137.
[39] He Z.J., Liang S.W., Ding Y., Liu Y., Chen Z.J., Relationships between $\delta^{18} \mathrm{O}$ in taproot of panax notoginseag and ecological factors, Journal of Nuclear Agricultural Sciences, 2016, 30(3), 556-564.

[40] Zhou H., Zheng X.J., Tang L.S., Li Y., Analysis on seasonal dynamics of $\delta^{18} 0$ and $\delta D$ in soil water at a Saline Desert site in the Southeastern Jungger basin, Journal of Desert Research, 2014, 31(1), 162-169.

[41] Fu Z.H., Wang Y.Q., An Z.S., Dynamics of deep soil moisture under different vegetation types in the wind-water erosion crisscross on the Chinese Loess Plateau, Journal of Earth Environment, 2015, 6(3), 188-194. 